\title{
Progressive renal failure after cisplatin therapy
}

\author{
S. M. Jakob, W. Arnold ${ }^{1}$ and H.-P. Marti \\ Division of Nephrology, Department of Medicine, 'Department of Pathology, University of Berne, Inselspital, Berne, \\ Switzerland
}

Key words: cisplatin; kidney failure

\section{Introduction}

Cisplatin is one of the most efficient solid-tumour chemotherapy agents. However, toxicity is a serious problem. A detailed review about modulators of cisplatin-induced side-effects was published recently [1]. In the kidney, cisplatin is freely filtered as well as secreted by tubular cells. Acute toxicity is mainly reflected by proximal tubular dysfunction [2,3]. Acute cisplatin nephrotoxicity is dose-dependent, but can be largely prevented by adequate hydration of the patients. In contrast to the good characterization of acute nephrotoxicity, controversy exists regarding deleterious longterm renal side-effects of this agent. There is little doubt that repeated applications of cisplatin may lead to chronic renal impairment. However, according to the literature, kidney function seems to stabilize on a lower functional level with no or very little further deterioration after completion of chemotherapy [4-6]. In this report we present two rare cases of chronic renal failure with relentless deterioration of renal function even many years after completion of cisplatin therapy.

\section{Case reports}

\section{Patient 1}

A white male, 24 years of age, was referred to the Division of Nephrology of the Inselspital Bern for evaluation of deteriorating kidney function.

In 1989 a diagnosis was made of embryonal teratoma in the right testicle with metastasis to many organs, including retroperitoneal lymph nodes and the right kidney. During the period of November 1989 until March 1990 six courses of chemotherapy were given, consisting of cisplatin ( $1400 \mathrm{mg}$, equal to $650 \mathrm{mg} / \mathrm{m}^{2}$

Correspondence and offprint requests to: Stephan M. Jakob Division of Nephrology, Department of Medicine, Inselspital CH-3010 Berne, Switzerland. of body surface), etoposid ( $7 \mathrm{~g}$ ) and ifosfamide ( $72 \mathrm{~g}$, in daily dosages of $1.1 \mathrm{~g} / \mathrm{m}^{2}$ of body surface). Prior to this treatment, renal function was slightly impaired with a creatinine level of $120 \mu \mathrm{mol} / \mathrm{l}$ (Figure 1). Kidney function normalized soon after initiation of chemotherapy, probably because of the cytotoxic effect on tumour deposits in the right kidney and retroperitoneal lymphatics. However, soon after completion of the six courses of cisplatin, relentless deterioration of the patient's renal function was observed (Figure 1).

On admission to the renal clinic in July 1994, the patient was free of tumour. He was obese $(132 \mathrm{~kg}, 182 \mathrm{~cm})$ with a normal blood pressure of $130 / 85 \mathrm{mmHg}$. Kidney function was impaired as reflected by a creatinine concentration of $180 \mu \mathrm{mol} / \mathrm{l}$. Urine analysis showed microhaematuria and proteinuria of $1.5 \mathrm{~g} / 24 \mathrm{~h}$. Computed tomography of the abdomen demonstrated normal kidneys without obvious parenchymal damage. A kidney biopsy was performed. Renal histology (40 glomeruli) was characterized predominantly by tubular alterations, such as atypically enlarged tubular cells with great variation in size and shape of the nucleus, mostly with visible nucleoli. In the interstitium, a slight infiltration of mononuclear leukocytes was seen (Figure 2). Electronmicroscopy disclosed no major glomerular abnormalit-

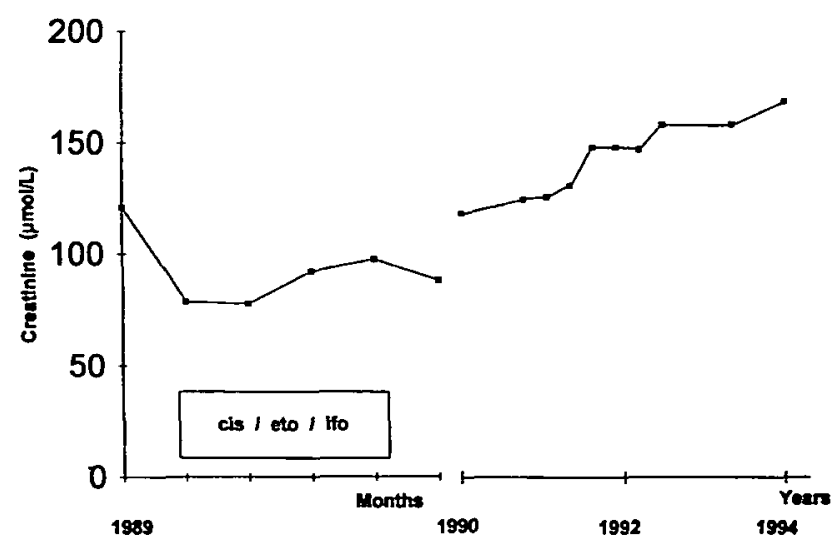

Fig. 1. Serum creatinine concentrations in patient 1 from 1989 (beginning of cisplatin treatment) until 1994, i.e. 4 years after completion of chemotherapy. Abbreviations: cis, cisplatin; eto, etoposide; ifo, ifosfamide. 


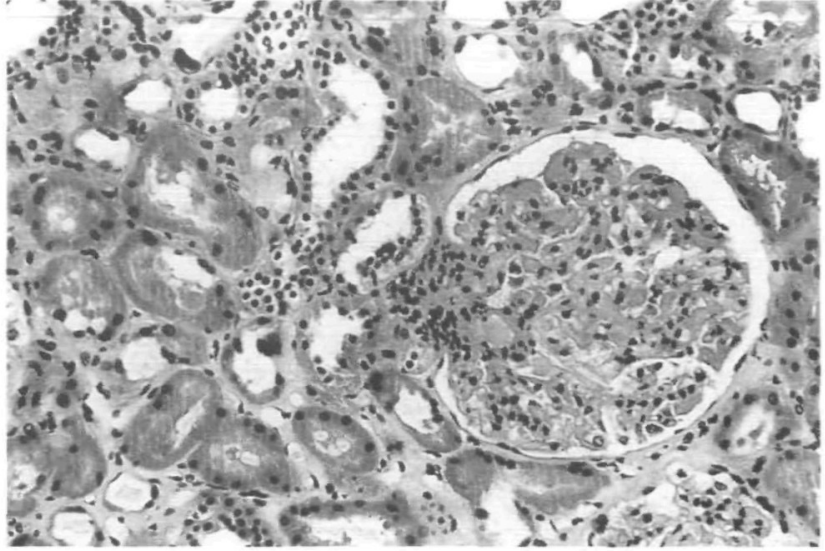

Fig. 2. Histology from patient 1 . The glomerulus, with the exception of prominent juxtaglomerular cells, is normal. The proximal tubular cells are variable in size. The tubular cell nuclei are slightly polymorphic. $\mathrm{H} \& \mathrm{E}, 175 \times$.

ies. The nuclear changes of tubular epithelia were also evident, in addition to minor cytoplasmic changes.

\section{Patient 2}

In this 51-year-old white male, seminoma of the right testicle with secondaries in retroperitoneal and hilar lymph nodes of the lung was diagnosed in 1981.

In January 1982, the right testicle was removed. A dose of 40 Gy each was applied to the para-aortic and iliac region, as well as to the supraclavicular areas and mediastinum. Because of tumour recurrence with metastases in both lungs, three courses of chemotherapy consisting of vinblastin, bleomycin, and cisplatin were given from June to August 1983. The patient responded well to this treatment; however, the creatinine level increased from 90 to $158 \mu \mathrm{mol} / 1$ (Figure 3); later, it decreased spontaneously to $100 \mu \mathrm{mol} / \mathrm{l}$. Because of reappearance of lung metastases, several courses of chemotherapy composed of vinblastin, bleomycin, and cisplatin alternating with cosmegen, etoposide and ifosfamide $\left(15 \mathrm{~g}\right.$ in daily dosages of $1.4 \mathrm{~g} / \mathrm{m}^{2}$ of body surface) were given in the period of March to July 1985. After completion of this chemotherapy, the patient's chronic renal failure progressed relentlessly. The patient remained in complete and sustained remission from his tumour; the total amount of cisplatin was in the order of $1150 \mathrm{mg}\left(650 \mathrm{mg} / \mathrm{m}^{2}\right.$ of body surface).

This patient was finally referred to the Division of Nephrology of the Inselspital Bern because of his impaired renal function, in August 1994. On admission he was in good general condition with a normal body weight of $65.5 \mathrm{~kg}$ in relation to his height. Physical examination was entirely normal with a blood pressure of $120 / 80 \mathrm{mmHg}$. However, the patient had chronic renal failure with a urea of $20.3 \mathrm{mmol} / \mathrm{l}$ and a creatinine of $359 \mu \mathrm{mol} / \mathrm{l}$. Analysis of a 24-h urine collection showed a mild proteinuria of $480 \mathrm{mg}$ and a severely reduced creatinine clearance of $25 \mathrm{ml} / \mathrm{min}$ (Figure 3). On ultrasonic examination, the kidneys were moder-

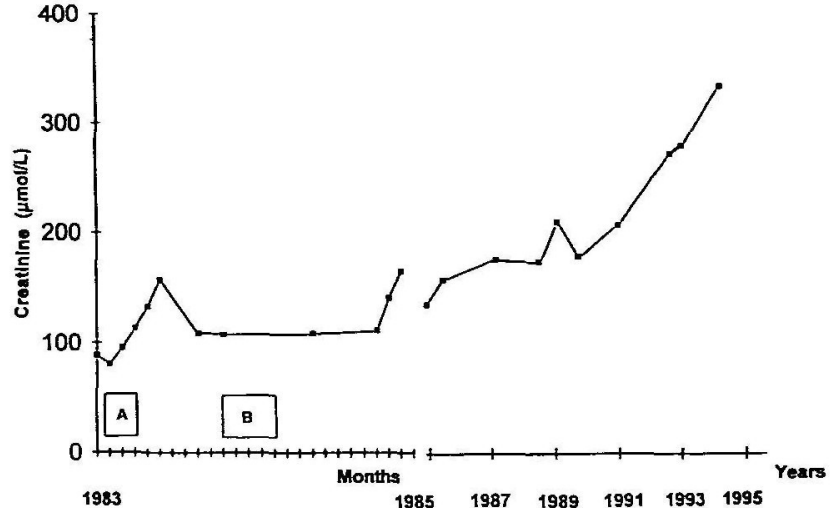

Fig. 3. Serum creatinine concentrations in patient 2 prior to chemotherapy in 1983 until 9 years after completion of cisplatin treatment in 1994. A, Cytotoxic therapy with vinblastin, bleomycin, and cisplatin; B, cytotoxic therapy with alternating vinblastin, bleomycin, cisplatin and cosmegen, etoposide, ifosfamide respectively.

ately reduced in size. There were no signs of a obstruction in the urinary tract. Urine analysis showed few granular casts, mild haematuria and proteinuria. The kidney biopsy (50 glomeruli) showed non-specific advanced glomerular and tubular scarring and interstitial infiltration predominantly by mononuclear leukocytes as well as focal areas of tubular hyperplasia.

\section{Discussion}

We describe two patients with normal serum creatinine levels prior to (patient 2) or shortly after (patient 1) initiation of cisplatin therapy, in whom chronic renal failure developed and progressed during the observation periods of 5 and 11 years respectively. With the exception of ifosfamide there were no other drugs with known renal toxicity. Side-effects of ifosfamide (mainly tubular toxicity) have been discussed and compared to those of cisplatin elsewhere [3,7]. According to Skinner et al. the combination of ifosfamide with other potential nephrotoxic drugs such as aminoglycosides, acyclovir, or cisplatin may increase the risk of nephrotoxic side-effects [8]. Brandis estimated the overall incidence of renal tubular dysfunction in patients treated with ifosfamide to vary between 10 and $20 \%$, with only $1-3 \%$ of cases showing severe clinical symptoms [3]. Chronic renal failure due to ifosfamide is extremly rare and occurred in patients treated with very high doses (daily dosages $>5 \mathrm{~g} / \mathrm{m}^{2}$ ) [9]. However, our patients were well below this limit.

To one patient radiotherapy to the para-aortic region was given (case 2). However, the kidneys were appropriately shielded and the dose affecting the kidneys was well below the accepted tolerance level of 20 Gy [10].

Therefore the progressive renal failure in both of our cases is most probably due to the use of cisplatin, possibly potentiated by ifosfamide. This is a very rare occurrence. In the literature we have found reports of 
Table 1. Mean cumulative cisplatin doses and percentage reduction of GFR in studies with observation periods of at least 12 months

\begin{tabular}{|c|c|c|c|c|c|c|}
\hline $\begin{array}{l}\text { Source of } \\
\text { data }\end{array}$ & Year & $\begin{array}{l}\text { Number } \\
\text { of patients }\end{array}$ & $\begin{array}{l}\text { Mean } \\
\text { age }\end{array}$ & $\begin{array}{l}\text { Cumulative } \\
\text { cisplatin dose. }\end{array}$ & $\begin{array}{l}\text { Mean \% } \\
\text { reduction } \\
\text { of GFR }\end{array}$ & $\begin{array}{l}\text { Mean observation } \\
\text { period (months) } \\
\text { ( } \mathrm{r}=\mathrm{R} \text { ange) }\end{array}$ \\
\hline Dentino $^{15}$ & 1978 & 15 & 22 & $300-500^{*}$ & 44 & 24 \\
\hline Fjeldborg ${ }^{4}$ & 1986 & 22 & 23 & $452^{* *}$ & 13 & $16-52(r)$ \\
\hline Groth $^{16}$ & 1986 & 25 & 24 & $60^{* *}$ & 29 & 12 \\
\hline Hansen $^{5}$ & 1988 & 34 & 34 & $583^{* *}$ & 10 & 65 \\
\hline Macleod $^{17}$ & 1988 & 22 & 31 & $670^{* * *}$ & 23 & 22 \\
\hline Hamilton ${ }^{18}$ & 1989 & 22 & 28 & $300-600^{*}$ & 22 & 30 \\
\hline Daugaard $^{19}$ & 1990 & 41 & uk & $400^{* *}$ & 12 & 24 \\
\hline Daugaard $^{19}$ & 1990 & 30 & uk & $600^{* *}$ & 36 & 24 \\
\hline Osanto $^{20}$ & 1992 & 43 & 30 & $483^{* *}$ & 15 & 49 \\
\hline Brillet $^{11}$ & 1993 & 1 & 31 & $540^{* * *}$ & $\mathrm{D}$ & 24 \\
\hline Uozumi $^{21}$ & 1993 & 17 & 52 & $698^{* * *}$ & 4 & 22 \\
\hline
\end{tabular}

* Range of dose $\left(\mathrm{mg} / \mathrm{m}^{2}\right.$ of body surface).

** Mean dose $\left(\mathrm{mg} / \mathrm{m}^{2}\right.$ of body surface).

*** Total dose $(\mathrm{mg})$.

$\mathrm{D}$, Haemodialysis required within 12 months.

uk, Unknown.

only three patients comparable to our two patients with chronic and progressive renal failure [11,12].

Brillet et al. reported four cases of end-stage renal failure due to cisplatin administration [11]. In two cases there was significant dehydration during cisplatin treatment, and one patient had one kidney removed a month prior to cisplatin exposure. In these three patients, dialysis was required within 15 days following chemotherapy. The fourth patient was treated with 5-fluorouracil, VP16, mitomycin and cisplatin $(540 \mathrm{mg})$. The creatinine concentration rose from $60 \mu \mathrm{mol} / 1$ to $340 \mu \mathrm{mol} / \mathrm{l}$. The patient developed endstage kidney disease within 1 year after termination of cisplatin therapy. Of these four patients, only the last one is really comparable to our two patients and is shown in Table 1, where only patients with an observation period of 12 months or longer are represented.

Rebmann $e t$ al. investigated the kidney function in 38 patients with testicular tumours [12]. The patients received one course of chemotherapy containing vinblastin, cyclophosphamide, actinomycin D, bleomycin, and cisplatin $120 \mathrm{mg} / \mathrm{m}^{2}$, followed by an unstated number of courses of vinblastin, adriblastin, leukeran, actinomycin, and cisplatin $50 \mathrm{mg} / \mathrm{m}^{2}$. There was either transient or permanent but stable deterioration in kidney function in 31 patients. Two of 31 developed chronic renal failure. In one patient the creatinine level remained stable at a value of $400 \mu \mathrm{mol} / \mathrm{l}$, the other patient developed end-stage renal disease. Both histories are very similar to that of our two patients, although Rebmann et al. did not state the observation period in his paper, and therefore these patients are not shown in Table 1.

Several investigators described a decrease in renal function during the period of cisplatin administration (Table 1). In these studies renal function seemed to stabilize with no $[4,15,18-20]$ or little $[5,17]$ further deterioration after cessation of cisplatin exposure. Only one patient was described with a marked decline in renal function in the study performed by Macleod [17]. In this patient the observation period was restricted to 12 months. Thus it remains unclear whether or not the renal function stabilized later on. Groth et al. observed a mean decrease in GFR of about $29 \%$ during the first 12 months after cessation of therapy in 25 patients [16]. The decline in GFR showed an exponential pattern within the observation period, suggesting no further decline after 12 months. Unfortunately Uozumi et al. did not indicate the exact time point of the assessment of the renal function in relation to the end of cytostatic therapy [21]. Therefore one cannot establish whether or not the GFR declined later on.

The mechanisms which give rise to the chronic nephropathy are conjectural. Cisplatin is known to be concentrated in the renal cortex, where it can be detected up to 4 weeks after cessation of treatment [13]. It may lead to direct and indirect toxic injuries. It has an effect on renal tubules, in analogy to the toxic effects of other heavy metals [14]. Cisplatin further causes a substantial decrease in median glomerular filtration rate and effective renal plasma flow, perhaps via an indirect vasomotoric effect that results in increased vascular resistance $[4,14]$. The combined vascular and tubular alterations may result in parenchymal atrophy, interstitial inflammation, and probably irreversible interstitial fibrosis. The reasons of the progressive deterioration and the self-perpetuation of the renal damage are unknown.

\section{References}

1. Treskes M, van-der-Vijgh WJ. WR2721 as a modulator of cisplatin- and carboplatin-induced side effects in comparison with other chemoprotective agents: a molecular approach. Cancer Chemother Pharmacol 1993; 33(2): 93-106

2. Chopra S, Kaufman JS, Jones TW et al. Cis-diamminedichloplatinum-induced acute renal failure in the rat. Kidney Int 1982; 21: 54-64 
3. Brandis $M$, v.d. Hardt $\mathrm{K}$, Zimmerhackl RB, Mohrmann M, Leititis J. Cytostatics-induced tubular toxicity. Clin Invest 1993; 71: 855-857

4. Fjeldborg P, Soerensen J, Helkjaer PE. The long-term effect of cisplatin on renal function. Cancer 1986; 58: 2214-2217

5. Hansen SW, Groth S, Daugaard G, Rossing N, Roerth $M$. Long-term effects on renal function and blood pressure of treatment with cisplatin, vinblastin and bleomycin in patients with germ cell cancer. $J$ Clin Oncol 1988; 6(11): 1728-1731

6. Brillet $G$, Deray $G$, Dubois $M$ et al. Chronic cisplatin nephropathy in rats. Nephrol Dial Transplant 1993; 8(3): 206-212

7. Suarez A, McDowell H, Niaudet P, Comoy E, Flamant F. Long-term follow-up of ifosfamide renal toxicity in children treated for malignant mesenchymal tumors: an International Society of Pediatric Oncology report. J Clin Oncol 1991; 9(12): 2177-2182

8. Skinner R, Pearson ADJ, Price L, Coulthard MG, Craft AW. Nephrotoxicity after ifosfamide. Arch Dis Child 1990; 65: 732-738

9. Willemse PHB, de Jong PE, Elema JD, Mulder NH. Severe renal failure following high-dose ifosfamide and mesna. Cancer Chemother Pharmacol 1989; 23: 329-330

10. Krochak RJ, Baker DG. Radiation nephritis. Clinical manifestations and pathophysiologic mechanisms. Urology 1986; 27: 389

11. Brillet $G$, Deray $G$, Lucsko $M$ et al. Insuffisance renale chronique terminale definitive apres traitement par le cisplatine. Nephrologie 1993; 14(5): 227-229

12. Rebmann $U$, Oehlmann $U$, Warnack $W$. Cisplatin induzierte nephrotoxische Nebenwirkungen der zytostatischen
Chemotherapie von Hodentumoren. Z Exp Chir Transplant Kuenstliche Organe 1990; 23(2): 83-85

13. Dobyan DC. Long-term consequences of cis-platinum-induced renal injury: a structural and functional study. Anat $\operatorname{Rec} 1985$; 212: 239-245

14. Meijer S, Sleijfer DT, Mulder NH et al. Some effects of combination chemotherapy with cis-platinum on renal function in patients with nonseminomatous testicular carcinoma. Cancer 1983; 51: 2035-2040

15. Dentino $M$, Luft FC, Yum MN, Williams SD, Einhorn LH. Long-term effect of cis-diamminedichloride platinum (CDDP) on renal function and structure in man. Cancer 1978; 41: 1274-1281

16. Groth S, Nielsen H, Sorensen J-B, Christensen AB, Pedersen AG, Rorth M. Acute and long-term nephrotoxicity of cisplatinum in man. Cancer Chemother Pharmacol 1986; 17(2): 191-196

17. Macleod PM. The effect of cisplatin on renal function in patients with testicular tumors. Clin Radiol 1988; 39: 190-192

18. Hamilton $C R$. The late effects of cis-platinum on renal function. Eur J Cancer Clin Oncol 1989; 25(2): 185-189

19. Daugaard G. Cisplatin nephrotoxicity: experimental and clinical studies. Dan Med Bull 1990; 37(1): 1-12

20. Osanto S, Bukman A, van Hoek F, Sterk PJ, de Laat JAPM Hermans J. Long-term effects of chemotherapy in patients with testicular cancer. J Clin Oncol 1992; 10: 574-579

21. Uozumi J. Platinum accumulation in the kidney and changes in creatinine clearance following chemotherapy with cisplatin in humans. Urol Int 1993; 3: 51-57

Received for publication: 29.8 .95

Accepted: 6.9 .95 